\title{
Air Pollution Caused by Coal-fired Power Plant in Middle Taiwan
}

\author{
Tase-Lung Chen \\ Department of Business Administration, Asia University, Taichung, Chinese Taipei
}

Email address:

longlong99.tw@yahoo.com.tw

\section{To cite this article:}

Tase-Lung Chen. Air Pollution Caused by Coal-fired Power Plant in Middle Taiwan. International Journal of Energy and Power Engineering. Vol. 6, No. 6, 2017, pp. 121-124. doi: 10.11648/j.ijepe.20170606.15

Received: November 15, 2017; Accepted: January 17, 2018; Published: February 3, 2018

\begin{abstract}
Achieving goals of industrial development and environmental sustainability is not the zero-sum game. But, contradiction exists between energy and air pollution. Taichung City, located in central Taiwan, has a world's second largest thermal power plant, carbon emissions ranked first in the world, a plant supply about 19\% of Taiwan's electricity consumption, emissions of coal in the air, of course, lead to serious air pollution in Taichung and neighboring areas. 15\% of the Taichung city's PM2.5 is discharged from the Taichung thermal power plant. The air quality information provided by the government is open and transparent. When the air pollution is serious, people demanded more and more from the government for clean air quality and require local governments to put pressure on coal-fired power plants. "2C", It's a dilemma to want cheap energy and clean air. Through the focus group discussion, integrating the best interests of the four groups: electricity producer, governments, experts and environmental groups, people, is possible but difficult. Different interest groups must compromise, in order to achieve the multiple goals on low electricity prices, low air pollution and good health.
\end{abstract}

Keywords: Coal-fired Power Plant, Air Pollution, PM2.5, Coal to Gas (CTG)

\section{Introduction}

Energy stability is an important foundation for the country, but the sustainable development of the environment is the way for people to live and work in health. Taichung coal-fired power plant provides $19 \%$ of Taiwan's electricity, and $15 \%$ of the Taichung city's PM2.5 being discharged from the Taichung thermal power plant. In recent years, air pollution has become a topic of concern all over the world. The government also regard improving air quality as the top priority. [1]

The dispute over energy and environmental protection comes from the interests and persistence of four groups:

(1) Electricity producer,

(2) Government,

(3) Experts \& environmental groups

(4) People

The study adopted literature review and focus group to solve the dilemma of cheap energy and clean air.

\section{Literature Review}

\subsection{Electricity Producers}

Electricity producers not only provide electricity to the public but also provide by-product, air pollution.

Taichung power plant, the largest fixed source of pollution in the Central Part of Taiwan, which is also the second largest fire power plant in the world. Taichung coal-fired power plant provides $19 \%$ of Taiwan's electricity. In 2016, Taipower System provided 225.792 billion $\mathrm{kWh}$ of electricity, of which $79.9 \%$ was thermal power, (of which $36.9 \%$ was coal-fired, $4.4 \%$ for fuel, $36 \%$ for gas, $2.6 \%$ for gas and electricity cogeneration). Recycling energy accounted for $5.1 \%$ (including water and gas symbiosis of garbage and biogas), pumped $1.5 \%$ of water, nuclear energy was $13.5 \%$. [2] [figure 1] In particular, the demand for power generation from certain fuels is driven by cyclical factors. Coal, natural gas, oil, renewables and other fuels have come in and out of vogue at 
different times over the years for various reasons, usually driven by costs of a particular fuel or regulations that tend to favor one fuel over another. [3] This situation is very similar to the power generation industry in Taiwan. At present, Taiwan is turning from nuclear power generation to green energy generation, such as wind turbines and solar power generation. Four coal-fired units at the Ernest C. Gaston Electric Generating Plant near Wilsonville, Alabama, were recently converted to burn natural gas. [3] Thermal power plants in Taiwan now increase the number of gas-fired generating units and gradually reduce the number of coal-fired generating units.

J Installed Capacity (41.04 GW)

\begin{tabular}{|c|c|}
\hline Purchased & $9,618 \mathrm{mw} 23 \%$ \\
\hline - Pumped storage hydro & $2,602 \mathrm{Mw} \quad 6 \%$ \\
\hline Oil & $3,325 \mathrm{MW} \quad 8 \%$ \\
\hline - Coal & $7,600 \mathrm{mw} 18 \%$ \\
\hline Gas & 10,635 Mw $26 \%$ \\
\hline Nuclear & $5,144 \mathrm{MW} 13 \%$ \\
\hline Renewable energy & $2,112 \mathrm{MW} \quad 5 \%$ \\
\hline
\end{tabular}

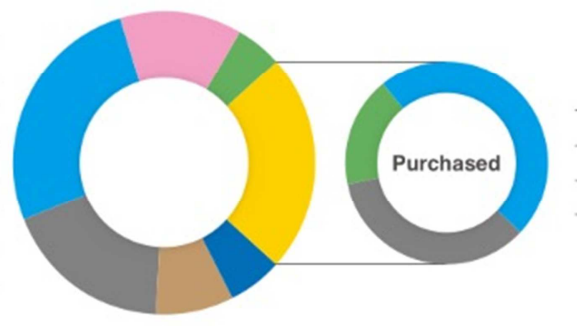

\begin{tabular}{lll}
\hline a IPP - Gas & $4,610 \mathrm{Mw}$ & $11 \%$ \\
\hline - IPP - Coal & $3,097 \mathrm{Mw}$ & $8 \%$ \\
\hline - Renewable energy & $1,911 \mathrm{Mw}$ & $5 \%$ \\
\hline
\end{tabular}

Power Generation (219,104 GWh)

\begin{tabular}{|c|c|}
\hline Purchased & 50,043 GWh $23 \%$ \\
\hline \multicolumn{2}{|c|}{ - Pumped storage hydro $3,023 \mathrm{GWh} \quad 1 \%$} \\
\hline Oil & $10,259 \mathrm{GWn}$ \\
\hline Coal & 57,080 GWn $26 \%$ \\
\hline Gas & $59,066 \mathrm{GWn} 27 \%$ \\
\hline Nuclear & $35,143 \mathrm{GWh} 16 \%$ \\
\hline Renewable energy & $4,490 \mathrm{GWh} \quad 2 \%$ \\
\hline
\end{tabular}
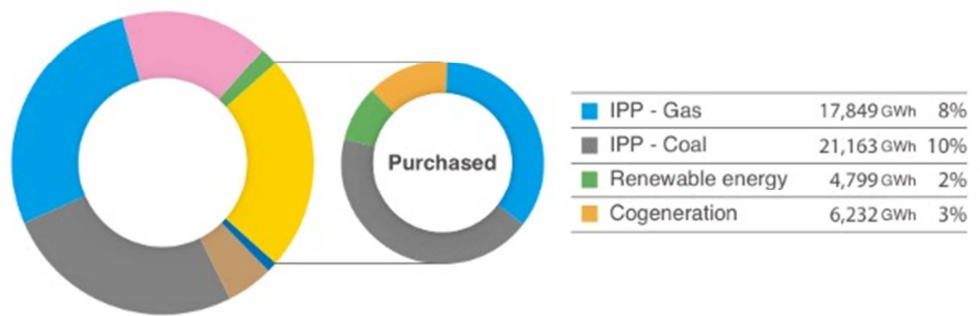

Figure 1. Taipower Install Capacity \& Power Generation.

\subsection{Government}

Taichung City Environmental Protection Agency listed data to prove "Taichung thermal power plant is the largest source of fixed pollution in Taichung," the city PM2.5 annual emissions of 8498 tons, all factories are regarded as fixed sources of pollution, emissions of 2690 tons, "half of which All contribute to the Taichung thermal power plant, with an emission of 1244 metric tons", which is equal to $15 \%$ of the city's PM2.5 being discharged from the Taichung thermal power plant. [1] [2] The Mayer of Taichung, Lin said, "we have already set out the conditions of restriction on applying for the license extension of Unit 9 in September this year (2017). Taichung coal-fired power plant must apply for firepower plant operation permission in accordance with the Taichung Raw Coal Controlling Ordinance and complete multiple plans. Those are cutting $40 \%$ of raw coal annual usage, using high quality raw coal and indoor coal bunker by the end of 2017." [2] He emphases in many speaking that there are two aspects related to the reduction of air pollution in Taipower: one is input, which is, reducing the amount of burning raw coal and improving the quality of raw coal. The other is output, which is, tightening emission standards and updating equipment performance. In addition, the conversion of coal-fired units to gas-fired units is carried out with fuel conversion, and $40 \%$ is set as the first stage goal. [4] [2] Actually, the total amount of Taichung power plant burning coal has been continuously reduced. Over the past two years, Taichung City Government have implemented more than 86 air pollution reduction measures, many of which are the first in Taiwan. The annual average PM2.5 concentration also ranges from $27 \mu \mathrm{g} / \mathrm{m} 3$ down in 2014 to $22.8 \mu \mathrm{g} / \mathrm{m} 3$ in 2015 . [1]

Mayer Lin said "We breathe the same air and we all have common expectations for a sustainable environment. Achieving goals of industrial development and environmental sustainability is not the zero-sum game. In order to improve the goal of decreasing air pollution, Taichung City Government continues to work hard!" [1].

National Taiwan University collaborated with The National Health Administration in the research of "Taiwan's burden of death attributable to major diseases that could be involved in risk factors", using the Taiwan Local Health Database. It included the National Health Interview Survey, the Surveillance Surveys in Taiwan and the National Nutritional Health Survey, Together with the EPD's air quality station data, as well as Taiwan's statistical data on cause of death.

Then it assess the impact of lifestyle, metabolism, environment and infection on the deaths of Taiwanese.

The study found that of the 13 risk factors, the three most important risk factors were hyperglycemia (14,900 deaths), smoking (11,500 men and 1,900 women, respectively), and high blood pressure (11,190 deaths) in 2009. Other risk factors ranked as PM2.5 exposure (8600 deaths), dietary risk factors (intake of high sodium and low fruits and vegetables, 7890 deaths), obesity (7620 deaths), lack of exercise (7400 deaths), drinking (6350 deaths). [5]

Of the 13 risk factors, only PM2.5 is an environmental factor. Traffic, coal-fired power plants and industrial pollution should be improved in Taiwan. Emissions of zero-emission 
electric vehicles and abolition of coal-fired power generation should be promoted. [5]

\subsection{Experts and Environmental Groups}

When Unit 3 at the Boundary Dam Power Station in Saskatchewan, Canada, switches on later this year after a lengthy refit, it will mark a historic moment for dirty coal power. It will be the first time that a commercial-scale plant supplying electricity to the grid captures and stores a large fraction of its carbon dioxide emissions. [3]

Concerns about the costs of carbon capture and storage (CCS) persist. The technology has progressed extremely slowly, reflecting a lack of enthusiasm for financing large projects. Yet the International Energy Agency (IEA) in Paris says that without CCS it could cost $40 \%$ more to decarbonize electricity enough to meet international climate targets by 2050. [3]

Dr. Chan also takes the Dalin Power Plant in Kaohsiung as an example. Since September 2012, the concentrations of PM10 and PM2.5 in the adjacent Linyuan Station have dropped after the stop working of Units 1 and 2 in the Dalin Power Plant. In particular, PM2.5 From 45.6 in 2011 to 29.5 in 2014, "it dropped by 16 in 3 years and the national standard was 15 , equivalent to a national standard of 3 years." [6]

PM2.5 is considered to be highly correlated with lung adenocarcinoma and has long been a first-class carcinogen of the World Health Organization (WHO). Due to the small size, less than $1 / 28$ of the hair diameter, small enough to carry heavy metals, dioxin and germs penetrate the respiratory system, directly to the chest, and the body with blood circulation. Taiwan's Healthy Air Action Alliance Dr. G. Ye pointed out that PM2.5 actually no safety value, only the lower the better. [6]

Assessment of the global burden of disease is based on epidemiological cohort studies that connect premature mortality to a wide range of causes. [7]

Opponents of public health and environmental regulations often try to manufacture uncertainty by questioning the validity of scientific evidence on which the regulations are based." Therefore, citizens or environmental groups must pay special attention to protesting against producers. Though most identified with the tobacco industry, this strategy has also been used by producers of other hazardous products. Power generation industry and tobacco industry in many places have similarities. [8]

\subsection{People}

The air quality information provided by the government is open and transparent, so people can learn the latest air quality from the information provided by governmental official website. [Figure 2] People can do precautionary measures when the air pollution is serious, but people are also demanding more and more from the government for clean air quality and require local governments to put pressure on coal-fired power plants.

People can get air quality information from Environmental
Protection Administration's Air Quality Monitoring Network. [2]

Taichung citizens have no direct power over Taichung thermal power plants, but Taichung's municipal government has the responsibility and authority. They can extend the plant operation permission or not, which decide Taichung thermal power plant can or cannot generate electricity by continuing to burn raw coal.

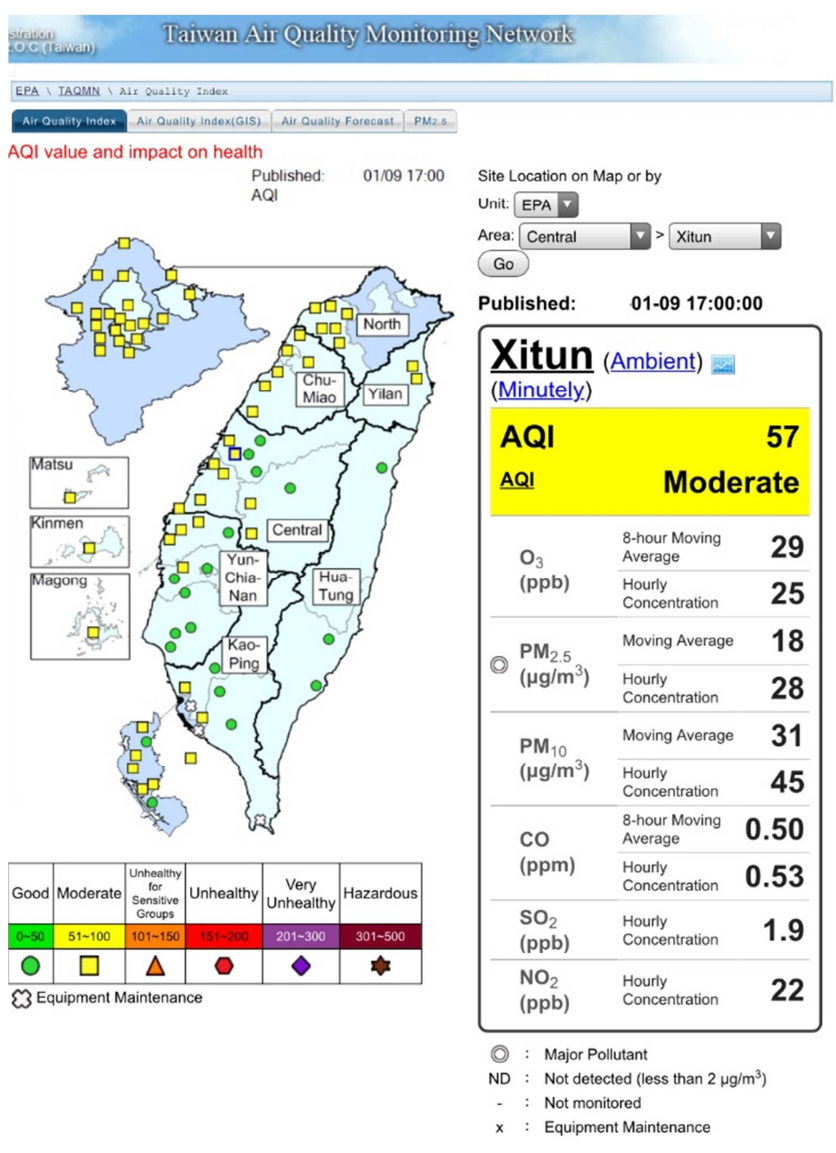

Figure 2. Taiwan AQI by Environmental Protection Administration.

\section{Methodology}

First, we reviewed other research using focus groups. "This study of focus group interviews showed three core stressors accounting for the various stressors in physicians' daily clinical work." [9] "The focus group interview thereby becomes a free zone, which not only enables the sensitive issue to be subjected to the group's reciprocal interpretation process, but also generates emancipatory processes." [10] "A focus group was conducted to obtain the perceptions and experiences of older adults concerning health-promoting self-care in their daily lives." [11] Then, to explore the different perspectives of the four groups, we formed a focus group. The participants included a municipal adviser, two public health expert and engineer with an environmental group background, a university vice president and a financial analyst. 


\section{Finding}

Through the focus group discussion, integrating the best interests of the four groups is possible but difficult.

Power plants hope stable power generation to achieve maximum revenue and profit. (Revenue US\$16 million profit \$2.1 million in 2015) The power plant also hopes to reduce the public's and environmental groups' protests.

Experts and environmental groups care about people's health and their interest, therefore strongly criticize the air pollution caused by power plants. Experts strongly urge the government to speed up the improvement of air quality and change coal-fired power generation to gas-fired power generation so as to reduce 2.5 to below 15 .

There are similarities and differences between the local government and the central government in their positions. They and the people want cheap energy (Now is 2.5NTD per $\mathrm{kWh}$ ) and clean air (reduce PM2.5 to below 15). However, local governments where the power plants are located are under greater pressure. The electricity price in Taiwan is the same. People in the air pollution area will not be able to make up for their health damage caused by air pollution even if they have money back from power plants. [12] According to financial analysts' estimates, if all the units in the Taichung thermal power plant are to be converted from coal to gas, the national electricity will increase by NT $\$ 0.16$ per KWh.

\section{Conclusion}

Through the literature review and focus groups to fully analyze the advantages and disadvantage of all parties, we found that integrating the best interests of the four groups: electricity producer, governments, experts and environmental groups, people, is possible but difficult. Different interest groups must compromise, in order to achieve the multiple goals on low electricity prices, low air pollution and good health.

\section{References}

[1] JL Lin, Taichung Mayor, Taichung government announcement, November, 2017.

[2] taipower.com.tw, Taiwan power company official website.

[3] S. Gossard, Babcock, Wilcox, Coal-To-Gas Plant Conversions in the U.S. POWER ENGINEERING, 6/18/2015.

[4] udn.com, "Did not mention the coal decrease schedule, extension of the nine units permit extension was returned", $11 / 13 / 2017$.

[5] WT Chen, "National Taiwan University announced the fatal risk factor PM2.5 fourth", Central News association, Jun 7, 2017.

[6] B. Tsai Environmental Alliance accused Taichung power plant as the source of Central Taiwan air pollution www.ettoday.net, Nov. 27, 2015.

[7] J. Lelieveld, J. S. Evans, A. Pozzer. The contribution of outdoor air pollution sources to premature mortality on a global scale Nature 525, 367-371 (17 Sep. 2015).

[8] Michaels D, Monforton C. Manufacturing uncertainty: Contested science and the protection of the public's health and environment. American Journal of Public Health, 2005; 9:S39-S48.

[9] Stressors Perceived by Physicians in Taiwan: A Focus Group Interview. Yen-Yuan Chen; Ming-Been Lee; Shih-Cheng Liao; Chia-Ming Chang Medical education, vol. 17-4, 12 / 01/2013, P165-174.

[10] Criticise Your Working Conditions! -Focus Group Interviews on Sensitive Topics. Rasmus Antoft; Anders Petersen Advances in Applied Sociology; vol 4-3, 3/2014.

[11] Using a Focus Group Study to Explore Perceptions of Health-Promoting Self-Care in Community-Dwelling Older Adults. HH Wang, MT Hsu, RH Wang. The Journal of Nursing Research; vol. 9-4, 09 / 01/2001, P 95-104.

[12] "The solution to the contradiction between energy and air pollution", focus group, 11/7/2017.

[13] taqm.epa.gov.tw, environmental protection administration executive yuan official website. 